\title{
Electrochemical Degradation of Atrazine in Aqueous Solution at a Platinum Electrode
}

\author{
M. Mamián, ${ }^{1,2}$ W. Torres, ${ }^{1}$ F.E. Larmat ${ }^{1, *}$ \\ ${ }^{1}$ Departamento de Química, Facultad de Ciencias Naturales y Exactas \\ Universidad del Valle, A.A. 25360, Cali-Colombia \\ ${ }^{2}$ Departamento de Química, Universidad del Cauca, Popayán-Colombia
}

Received 25 April 2008; accepted 15 October 2008

\begin{abstract}
Atrazine is a highly used herbicide and it has been found in both deep and superficial waters. Its solubility in water is reduced and is relatively stable in humid environments, where it has a half-life of one hundred days. Atrazine can be degraded by oxidative photolysis or by microorganisms. It is moderately toxic in humans, animals and plants, because it can be absorbed by inhalation, ingestion or through the skin.

In this work, we study the degradation of atrazine in aqueous solution using current controlled electrolysis at a platinum electrode. The effects of $\mathrm{pH}$, current magnitude and direction, and temperature, were evaluated. The atrazine decomposition was monitored during electrolysis by UV-Vis spectrophotometry; quantification of atrazine was done by GC/MS, and quantification of cyanuric acid was done by HPLC.

It was found that at $25^{\circ} \mathrm{C}$ in acid media, atrazine is degraded partially to cyanuric acid with formation of persistent intermediate compounds, but at $60{ }^{\circ} \mathrm{C}$ atrazine is completely degraded to cyanuric acid. The TOC results indicate no electrochemical combustion and no mineralization was observed under the experimental conditions studied.
\end{abstract}

Keywords: atrazine, electrochemical degradation, cyanuric acid, TOC.

\section{Introduction}

The compound 2-chloro-4-ethylamino-6-isopropylamino-1,3,5-triazine, or atrazine, is a highly used herbicide of pre- and post-emergency. Atrazine, which has been found in both deep and superficial waters, presents a low solubility in water $\left(1.6 \times 10^{-4} \mathrm{M}\right.$ at $\left.20^{\circ} \mathrm{C}\right)$ and it is relatively stable in aqueous environments and soils, where it has a half-life of one hundred days. Atrazine can be degraded by oxidative photolysis or microbial action. [1] Moderately toxic to humans and other animals, it can be absorbed through inhalation, oral route or the skin. The degradation of this herbicide has been studied by means of biological [1]

\footnotetext{
* Corresponding author. E-mail address: flarmat@univalle.edu.co
} 
(bacterial decomposition, metabolization in plants) and physicochemical methods $[2,3]$ (adsorption on solid adsorbents and oxidative degradation with free radicals), visible or ultraviolet radiation, ultrasound and microwaves [4-9]. The final products detected after oxidative degradation are cyanuric acid as predominant compound and other substituted triazines.

Alternatively, electrochemical techniques can be used for atrazine degradation, where catalytic properties of several electrode materials for producing oxidative or reductive reactions are well known. These methods can readily be coupled with other chemical or biological methods. For example, by means of reductive electrolysis in aqueous acidic medium, or on mercury electrodes, where atrazine and other chlorinated triazines lose chlorine or an alkyl group. [4,10]

In this work, we study the electrochemical degradation of atrazine at a platinum electrode at different conditions of $\mathrm{pH}$, temperature, anodic and cathodic current density, in the electrochemical cell.

\section{Experimental}

\section{Reagents}

Atrazine (CAS: 1912-24-9), 99\% pure (Supelco), was used without further purification. Cyanuric acid, (CAS: 108-80-5), 98\% pure (Fluka) was used as received. Sodium phosphates, 98\% pure (Carlo-Erba), were used to adjust $\mathrm{pH}$. Acetonitrile, dichloromethane, methanol and $n$-hexane (Mallinckrodt and CarloErba, respectively), HPLC grade, were used for the chromatographic analyses. Potassium acid phthalate (CAS: 877-24-7), 99\% pure was used in the TOC analyses. Deionized water (milliQ-millipore) was used in all experiments.

\section{Electrochemical system}

All electrolysis were performed in an two-compartment electrochemical cell (100 $\mathrm{mL}$ each), separated by a glass membrane ( $2 \mu \mathrm{m}$ pore diameter). Two $2.15 \mathrm{~cm}^{2}$ mesh platinum electrodes were used as anode and cathode and counter electrode, respectively. In the set of experiments where the working platinum electrode was used as a cathode, atrazine did not degrade.

The cell was driven by a 50-300 mA current source. The effect of $\mathrm{pH}$, temperature and current density over the oxidative reaction of atrazine and cyanuric acid was studied. The $\mathrm{pH}$ was fixed between 0.8 and 11.5 by using phosphate buffer solutions. The reaction was performed at 25 and $60{ }^{\circ} \mathrm{C}$ and 0.023 and $0.12 \mathrm{Acm}^{-2}$. Constant stirring was used in all experiments. Aliquots of $3.0 \mathrm{~mL}$ were drawn from the cell at 0, 5, 15, 30, 60, 120 and 240 minutes of electrolysis for chromatographic and spectroscopic analyses.

\section{$U V$-Vis spectrophotometry}

UV-Vis spectra were taken with a Shimadzu, model UV-160A spectrophotometer. The spectra were recorded between $200-600 \mathrm{~nm}$ at a scan rate of $30 \mathrm{~nm} / \mathrm{s}$ in a $1.0 \mathrm{~cm}$ quartz cell.

\section{Atrazine quantification}


Atrazine in aqueous solution was extracted from the electrolysis medium using methylene chloride as organic phase (73.2 \% of recovery). The extracts were dried and reconstituted to $0.5 \mathrm{~mL}$ with $n$-hexane. These samples were analyzed with a Shimadzu GC/MS-QP2010 system with a Restek XTI-5 column (30 m x $0.3 \mathrm{~mm} \times 0.25 \square \mathrm{m}$ ), helium as mobile phase, and the quadrupole detector operated in single ion monitoring mode, SIM. The GC column temperature was set at $80^{\circ} \mathrm{C}$ for 1 minute, ramped to $180{ }^{\circ} \mathrm{C}$ at $30^{\circ} \mathrm{C} / \mathrm{min}$ then to $230^{\circ} \mathrm{C}$ at 10 ${ }^{\circ} \mathrm{C} / \mathrm{min}$ and kept at $230{ }^{\circ} \mathrm{C}$ for 6 minutes. For quantification, the peak at $\mathrm{m} / \mathrm{z}=215$ [molecular ion, $\mathrm{C}_{8} \mathrm{H}_{14} \mathrm{~N}_{5} \mathrm{Cl}^{+}$] was used.

\section{Cyanuric acid quantification}

A HPLC Perkin-Elmer LC 100El chromatograph with a Hypersil ODS column (length $=125 \mathrm{~mm}$, internal diameter $=5 \mu \mathrm{m}$ ) was used. A mixture of $2 \%$ methanol, $98 \%$ phosphate buffer solution $(\mathrm{pH}$ 6.94) was used in an isocratic mode with a constant flow of $0.7 \mathrm{~mL} / \mathrm{min}$. Detection was done with an UV Hewlett Packard unit at $\lambda=215 \mathrm{~nm}[11]$.

\section{Total organic carbon analysis}

TOC of the atrazine electrolysis solution was determined in a TOC analyzer Shimadzu Model TOC-VWS, calibrated by using potassium acid phthalate. The detection and quantification limits were 1.0 and $3.0 \times 10^{-2} \mathrm{mM}$, respectively.

\section{Results and discussion}

Experimental design

The experimental conditions of the electrolytic experiments are shown in Table 1.

Table1. Experimental conditions used for the electrolysis of atrazine $5.0 \times 10^{-3} \mathrm{mM}$.

\begin{tabular}{|c|c|c|c|}
\hline $\mathbf{p H}$ & Current density $\left(\mathbf{A c m}^{-\mathbf{2}}\right)$ & Working electrode & Temperature $\left({ }^{\mathbf{0}} \mathbf{C}\right)$ \\
\hline 6.9 & 0.02 & Cathode & 25 \\
6.9 & 0.02 & Anode & 25 \\
6.9 & 0.07 & Anode & 25 \\
6.9 & 0.07 & Cathode & 25 \\
6.9 & 0.12 & Anode & 25 \\
3.5 & 0.07 & Anode & 25 \\
3.5 & 0.07 & Cathode & 25 \\
0.8 & 0.07 & Cathode & 25 \\
0.8 & 0.07 & Anode & 25 \\
0.8 & 0.07 & Cathode & 60 \\
0.8 & 0.07 & Anode & 60 \\
10.5 & 0.07 & Anode & 25 \\
10.5 & 0.07 & Cathode & 25 \\
\hline
\end{tabular}




\section{Monitoring reaction by $U V$ spectroscopy}

The UV spectrum of atrazine in aqueous solution (natural $\mathrm{pH}$ ) exhibits a main band centered at $222 \mathrm{~nm}$ and a band of minor intensity at $270 \mathrm{~nm}$. Cyanuric acid (found as final predominant product) absorbs below $235 \mathrm{~nm}$ without reaching a maximum above $200 \mathrm{~nm}$. However, at $\mathrm{pH}$ 10.0, cyanuric acid shows a band with a maximum at $235 \mathrm{~nm}$. Since the molar absortivities for cyanuric acid between 200 and $250 \mathrm{~nm}$ are very small compared to those of atrazina, it is possible to follow the decay of atrazine by monitoring the absorbance at $222 \mathrm{~nm}$ because at this wavelength, interference by cyanuric acid can be neglected.

\section{Anodic electrolysis}

The degradation rates of atrazine increase with anodic current density up to 0.12 $\mathrm{Acm}^{-2}$ as shown in Fig.1.

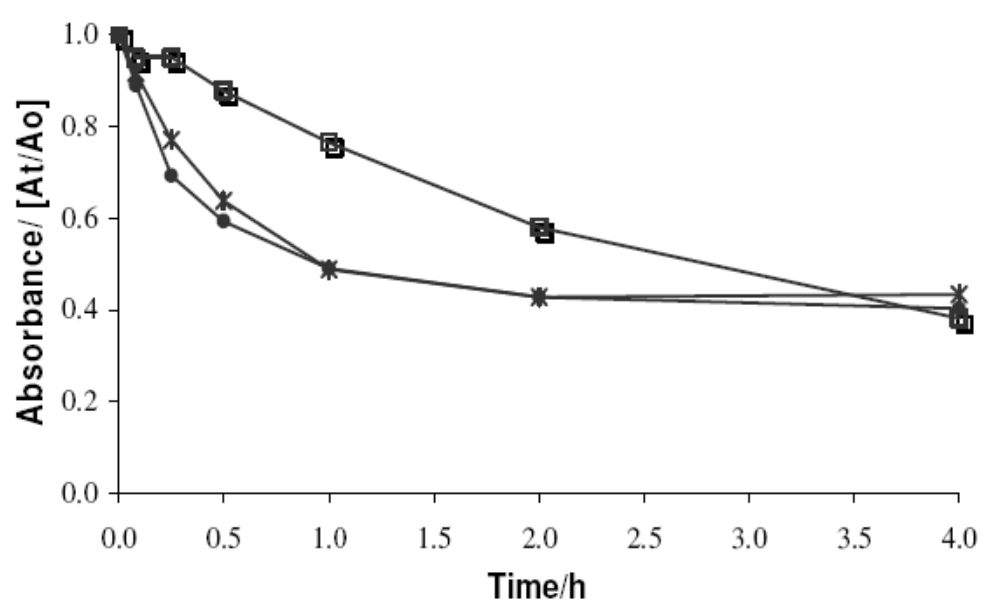

Figure 1. Normalized variation of absorbance at $222 \mathrm{~nm}$, during oxidative electrolysis of atrazina at $\mathrm{pH}=6.9$ and $25^{\circ} \mathrm{C}$. Current densities, in $\mathrm{Acm}^{-2}: 0.12$ (asterisks), 0.07 (full circles), and 0.02 (white squares).

Higher current densities do not change the degradation rates, indicating that the reaction rate becomes limited by mass transfer towards the anode. In another set of experiments, in which the working platinum electrode was used as a cathode, atrazine did not degrade.

\section{pH effect}

As shown in Fig. 2, at pH 0.8 and 3.5, the absorbance decreases linearly at the beginning of the reaction, reaching steady state after ca. 2 hours. At $\mathrm{pH} 6.9$, the absorbance changes slowly for $1.5 \mathrm{~h}$ and then decays faster. At $\mathrm{pH} 10.5$, the absorbance decreases by only ca $10 \%$ after $4 \mathrm{~h}$ of electrolysis, suggesting that atrazine follows different mechanisms of degradation with $\mathrm{pH}$. 


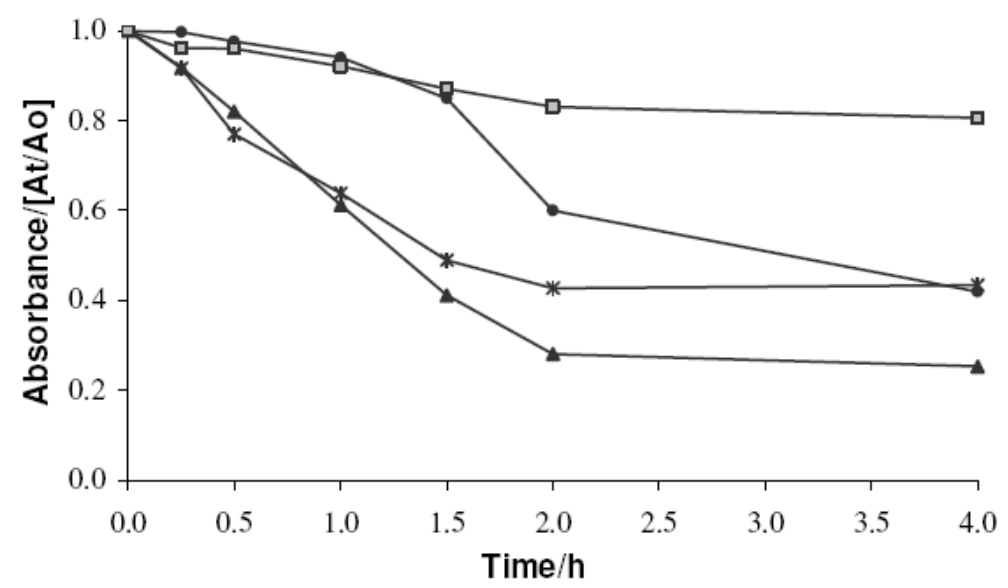

Figure 2. Normalized variation of atrazine absorbance at $222 \mathrm{~nm}$ during oxidative electrolysis at $0.007 \mathrm{~A} \mathrm{~cm}^{-2}$ and temperature of $25^{\circ} \mathrm{C}$. Reaction $\mathrm{pH}, 0.8$ (triangles), 3.5 (asterisks), 6.9 (circles), and 10.5 (white squares).

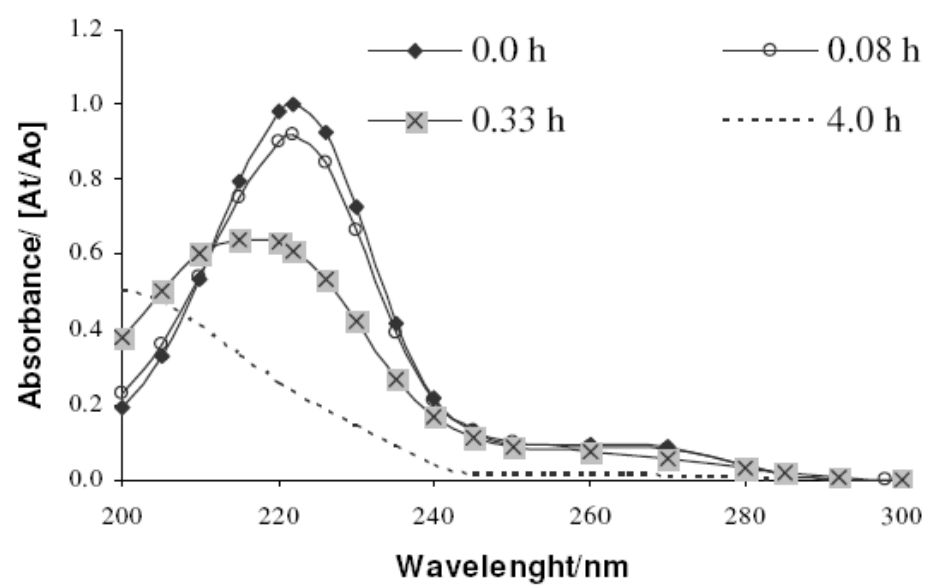

Figure 3. Variation of the UV spectrum during atrazine electrolysis at $0.07 \mathrm{Acm}^{-2}$, temperature of $25^{\circ} \mathrm{C}$, and $\mathrm{pH}=0.8$.

Fig. 3 shows the variation of atrazine spectra during the anodic electrolysis at $0.07 \mathrm{~A} \mathrm{~cm}^{-2}$, temperature of $25^{\circ} \mathrm{C}$, and $\mathrm{pH} 0.8$. Under these conditions, atrazine is protonated and the spectrum registered after 4 hours of electrolysis shows the decrease of the main band at $220 \mathrm{~nm}$, and residual absorption between 200 to 240 $\mathrm{nm}$, indicating that the products of the reaction are aromatic. At $\mathrm{pH} 0.8$, the absorbance at $222 \mathrm{~nm}$ decreases by $70 \%$ in $4.0 \mathrm{~h}$. In basic medium, during the same time scale, the atrazine conversion is negligible. Several degradation routes of atrazine and similar compounds have been proposed. These routes involve free radicals [12-14]. The following reactions have been proposed:

- substitution of the chlorine atom by a hydroxyl group as initial step of degradation;

- reduction of the amine groups, with protonation preceding electron transfer;

- oxidation of alkyl groups of the amines to produce carbonyl or hydroxyl groups. 
Fig. 4 shows two possible degradation products of atrazine. The acidity of the reaction medium has a marked influence in the degradation of atrazine since complete protonation affects the substitution at the ring and produces one or several dealkylated products. The susceptibility of electrophilic attack will be similar for the carbons of the ring bonded to the amines. The steric hindrance is probably bigger for the carbon next to the ethylamine group because it doesn't present chain ramifications and it is one carbon short with respect to the isopropylamine.<smiles>CCNc1nc(Cl)nc(NC(C)C)n1</smiles>

1<smiles>Nc1nc(N)nc(Cl)n1</smiles>

2<smiles>Nc1nc(N)nc(O)n1</smiles>

3

Figure 4. Atrazine (1) and two probable products of the degradation process. Simazine di-dealkylated (2) and ammeline (3).

The amino substituents in the deprotonated atrazine species shows low reactivity and the chlorine is likely to be replaced by a hydroxyl group. In spite of the electron donating characteristics of amines that activate the aromatic ring, the UV spectra suggest that an alkaline medium does not favor the electrochemical reaction. Under the experimental conditions studied, formation of cyanuric acid was observed at the end of electrolysis. Fig. 5 shows the structure of this compound.<smiles>Oc1nc(O)nc(O)n1</smiles>

Figure 5. Structure of the cyanuric acid.

Spectroscopic monitoring of the reaction allowed selecting the best conditions for atrazine, as shown in Table 2.

Table 2. Experimental conditions selected for the quantification of atrazine electrolysis.

\begin{tabular}{|c|c|c|c|}
\hline $\mathbf{p H}$ & Current density $\left(\mathbf{A c m}{ }^{-2}\right)$ & Electrode & T $\left(\mathbf{~}^{\mathbf{}} \mathbf{C}\right)$ \\
\hline 0.8 & 0.07 & Anode & 25 \\
3.5 & 0.07 & Anode & 25 \\
7.0 & 0.07 & Anode & 25 \\
0.8 & 0.07 & Anode & 60 \\
\hline
\end{tabular}


Fig. 6 shows the concentration variations of atrazine and cyanuric acid during electrolysis at different $\mathrm{pH}$. Consistent with the UV spectra, low $\mathrm{pH}$ favors the degradation of atrazine, as observed in Table 3.

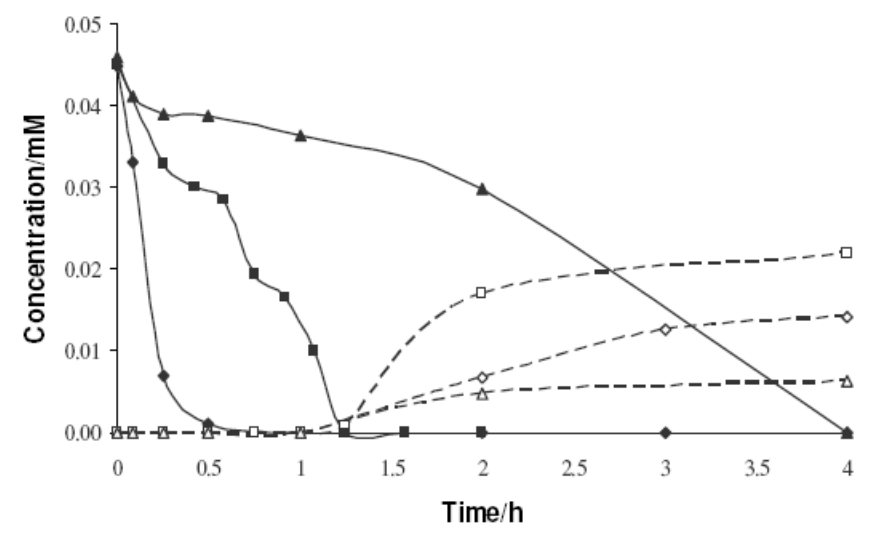

Figure 6. Variation of atrazine (continuous lines) and cyanuric acid (dashed lines) with time at pH: 0.8 (diamonds), 3.5 (squares) and 7.0 (triangles), current density of 0.07 $\mathrm{Acm}^{-2}$ and temperature of $25^{\circ} \mathrm{C}$.

Table 3. Percentages of atrazine conversion after $0.5 \mathrm{~h}$ of electrolysis.

\begin{tabular}{|c|c|}
\hline Atrazine conversion (\%) & $\mathbf{p H}$ \\
\hline 97.5 & 0.8 \\
36.5 & 3.5 \\
13.9 & 7.0 \\
\hline
\end{tabular}

Fig. 7 shows the effect of temperature on the degradation of atrazine: at $60{ }^{\circ} \mathrm{C}$, $93.3 \%$ of atrazine is converted to cyanuric acid, while at $25^{\circ} \mathrm{C}$ only $31.3 \%$ are oxidized. The conversion from intermediates to cyanuric acid is faster and the final product appears after total degradation of atrazine at the higher temperature. The benefit to do the electrolysis at higher temperature is the elimination of side reactions and the obtaining of only one product. Finally, the TOC analyses do not show electrochemical combustion and no mineralization of the electrolytic media was observed.

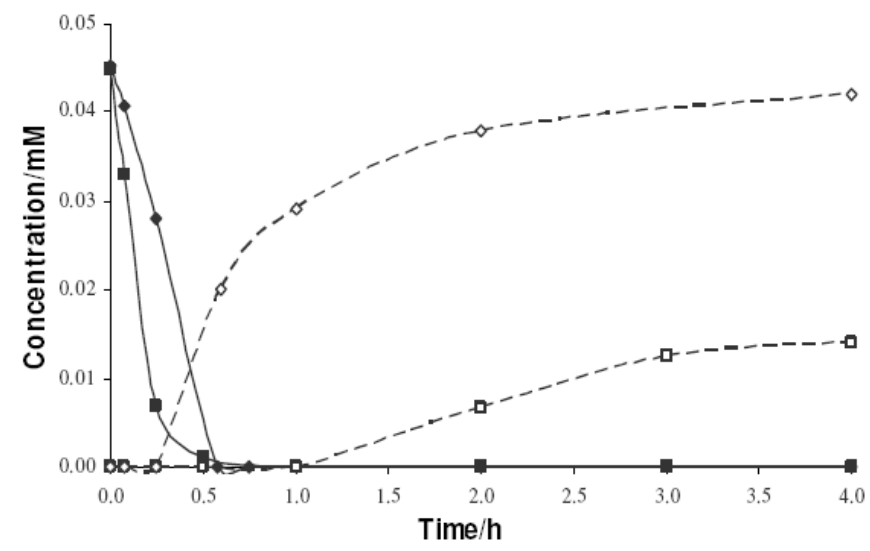

Figure 7. Variation of atrazine concentration (continuous line) and cyanuric acid (dotted line) at $\mathrm{pH}=0.8$ and temperatures of 25 (squares) and $60{ }^{\circ} \mathrm{C}$ (diamonds). 


\section{Conclusions}

In aqueous acidic media, atrazine is degraded at a platinum anode. At $60{ }^{\circ} \mathrm{C}$, atrazine is degraded completely to cyanuric acid in 4 hours of electrolysis. At 25 ${ }^{\circ} \mathrm{C}$ atrazine is partially degraded and intermediates that persist after 4 hours of electrolysis. No mineralization of this heterocyclic compound was observed in any experiment.

\section{Acknowledgments}

Funding for this project was provided by Universidad del Valle. We acknowledge Mrs. Alexandra Lucero, from the Laboratory of the Plant of Treatment of Residual Waters of the city of Cali, Colombia, for the TOC experiments.

\section{References}

1. S. Nélieu, L. Kerhoas, J. Einhorn, Degradation of atrazine into ammeline by combined ozone/hydrogen peroxide treatment in water, Environm. Sci. \& Technol. 34 (2000) 430-437.

2. H. Krysová, J. Jirkovský, J. Krýsa, G. Mailhot, M. Bolte, Comparative kinetic study of atrazine photodegradation in aqueous $\mathrm{Fe}\left(\mathrm{ClO}_{4}\right)_{3}$ solutions, Appl. Catalysis 40 (2003) 1-12.

3. E. Pelizzetti, V. Maurino, C. Minero, V. Carlin, E. Pramauro, O. Zerbinatl, M. Tosato, Photocatalytic degradation of atrazine and other s-triazine herbicides, Environm. Sci. \& Technol. 24 (1990) 1559-1565.

4. K.H. Chan, W. Chu, Atrazine removal by catalytic oxidation processes with or without UV irradiation. Part II: an analysis of the reaction mechanisms using LC/ESI - tandem mass spectrometry, Appl. Catalysis B: Environmental 58 (2005) 165-174.

5. C.L. Bianchi, C. Pirola, V. Ragaini, E. Selli, Mechanism and efficiency of atrazine degradation under combined oxidation processes, Appl. Catalysis B: Environmental 64 (2006) 131-138.

6. M. Hincapié, A. Perez, G.B. Peñuela, M.I. Maldonado, O. Malato, P. Fernandez, C. Ibañez, I. Oller, W. Gernjak, S. Malato, Degradation of pesticides in water using solar advanced oxidation processes, Appl. Catalysis B: Environmental 64 (2006) 272-281.

7. T.A. McMurray, P.S.M. Dunlop, A.J. Byrne, The photocatalytic degradation of atrazine on nanoparticulate $\mathrm{TiO}_{2}$ films, J. Photochemistry and Photobiology A: Chemistry 182 (2006) 43-51.

8. G. Zhanqi, Y. Shaogui, T.N. Sun, Microwave assisted rapid and complete degradation of atrazine using $\mathrm{TiO}_{2}$ nanotube photocatalyst suspensions, $J$. Hazardous Materials 145 (2007) 424-430.

9. M. Lapertot, S. Ebrahimi, S. Dazio, A. Rubinelli, C. Pulgarin, Photo-Fenton and biological integrated process for degradation of a mixture of pesticides, J. Photochemistry and Photobiology A: Chemistry 186 (2007) 34-40. 
10. L. Pospísilil, R. Trsková, R. Fuoco, M. Colombini, Electrochemistry of striazine herbicides: reduction of atrazine and terbutylazine in aqueous solutions. J. Electroanal. Chem. 395 (1995) 189-193.

11. T. Dombek, D. Davis, J. Stine, D. Klarup, Degradation of terbutylazine (2chloro-4-ethylamino-6-terbutylamino-1,3,5-triazine), deisopropyl atrazine (2-amino-4-chloro-6-ethylamino-1,3,5-triazine), and chlorinated dimethoxy triazine (2-chloro-4,6-dimethoxy-1,3,5-triazine) by zero-valent iron and electrochemical reduction. Environm. Pollution 129 (2004) 267-275.

12. R. Cantú, O. Evans, F. Kawahara, J. Shoemaker, A. Dufour, An HPLC method with detection, $\mathrm{pH}$ control, and reductive ascorbic acid for cyanuric acid analysis in water, Analytical Chemistry 72 (2000) 5820-5828.

13. M. Azenha, H. Burrows, L. Canle, R. Coimbra, M. Fernandez, M. García, M. Peiteado, J. Santaballa, Kinetic and mechanistic aspects of the direct photodegradation of atrazine, atraton, ametryn and 2-hidroxyatrazine by 254 nm light in aqueous solution, J. Phys. Org. Chem. 16 (2003) 498- 503.

14. S. Chan, S. Tao, R. Dawson, Treatment of atrazine by integrating photocatalytic and biological processes, Environm. Pollution 131 (2004) 4554. 